\title{
Comparison between the Effects of Alfentanil, Lidocaine and Their Composition in Controlling the Hemodynamic Responses at the Time of Awake Extubation of Patients
}

\author{
Ali Alizadeh1, Mahmoud Aghaziarati2 ${ }^{*}$, Nasim Zarin ${ }^{3}$ \\ ${ }^{1}$ Assistant Professor of Medical Science University, Qazvin, Iran \\ ${ }^{2}$ Anesthesiologist of Medical Science University, Tehran, Iran \\ ${ }^{3}$ Assistant Professor of Anesthesiology, Medical Science University, Qazvin, Iran \\ Email: *mziarati1970@gmail.com
}

How to cite this paper: Alizadeh, A., Aghaziarati, M. and Zarin, N. (2017) Comparison between the Effects of Alfentanil, Lidocaine and Their Composition in Controlling the Hemodynamic Responses at the Time of Awake Extubation of Patients. International Journal of Clinical Medicine, 8, 430438.

https://doi.org/10.4236/ijcm.2017.86041

Received: February 7, 2017

Accepted: June 25, 2017

Published: June 28, 2017

Copyright $\odot 2017$ by authors and Scientific Research Publishing Inc. This work is licensed under the Creative Commons Attribution International License (CC BY 4.0).

http://creativecommons.org/licenses/by/4.0/

\begin{abstract}
Background and aim: Instability in the hemodynamic symptoms has been common at the time of extubation in patients and the cause to create the side effects. The aim of this research was to study the effect of injection of Alfentanil, Lidocaine and their composition in reduction of side effects arising from extubation. Materials and methods: 172 patients (20 - 40 years old) that referred to Shahid Rajaee Hospital in 2014 and had been under the orthopedic surgery, were divided randomly and by using colored cards into four equal groups (43 patients in each group). Alfentanil ( 5 microgram/kilogram) was injected to the first group. The second group received Lidocaine (1 milligram/ kilogram). The composition of these two drugs was injected to the third group and the normal equal volume of Saline was injected to the fourth group which was the control group. The means of systolic and diastolic blood pressure, average arterial pressure and the number of heartbeat at the time of extubation were measured and registered 1, 5, 10, 15 and 20 minutes after extubation. Also, the amount of situation of bucking after extubation was registered in the groups. Results: The demographic results were similar in all groups. The mean of systolic blood pressure and number of heartbeats in the group of $\mathrm{Al}$ fentanil and composition of Alfentanil-Lidocaine had significant reduction $(\mathrm{p}<0.05)$ in comparison with the control and Lidocaine group. The mean of diastolic blood pressure and average arterial pressure hadn't significant difference between the control group and other groups ( $p>0.05$ ). The situation of bucking in three treatment groups had significant reduction in comparison with control group. Conclusion: Alfentanil and composition of it with Lidocaine both had caused reducing the systolic blood pressure and heartbeats.
\end{abstract}




\section{Keywords}

Alfentanil, Lidocaine, Hemodynamic Responses

\section{Introduction}

Waking up from general anesthesia (emergence) and extubation are two important stages of anesthesia; because, numerous problems can occur at this time. Although, intubation has attracted much attention to itself especially when the airway has been affected by problem, extubation of patients hasn't been considered so much [1] [2] [3]. The anesthesia specialists know that a short time after extubation causes many incidents and the incidents like larynx spasm, aspiration, lack of complete openness of airway, insufficient pulmonary ventilation and severe coughs can occur that all cause emerging hypoxemia that this problem can cause emerging myocardial ischemia especially in the patients that are affected by the coronary arteries disease [4] [5].

Many techniques can cause reducing these harmful effects [6]. Narcotics, beta-adrenergic drugs and the blocker drugs of calcium canal have been studied vastly [7].

Lidocaine by competition with calcium in sitting on the neural membrane receptors causes controlling the passage of sodium from beyond the cellular membrane and the depolarization stage reduces the potential of the act [8]. These effects are started by revocable stabilization of neural cells membrane as the result of reduction of permeability of this membrane to the sodium ion and the conduction of the neural waves is stopped. In the event of absorption of many amounts of Lidocaine, it can have stimulator effect and then weakening effect on the central neural system [9] and [10].

The side effects of this drug include hands tremor, restlessness, ear buzz, sight darkness or diplopia that with much consumption, it also can cause reducing the heartbeat, spasm, cardiac arrest, asthma, respiratory arrest. Also, Lidocaine has caused reducing the activity of efferent $\mathrm{C}$ fibers of larynx and it causes suppressing the cough reflex and somehow it has succeeded in reducing the hemodynamic responses [11].

The narcotic drugs are usually used to reduce the side effects arising from extubation and among them, two drugs of Alfentanil and Remifentanil due to the start of quicker effect have been more common than other narcotic drugs in the recent years [12].

Therefore, the executors of plan intended to use of a method that has the least hemodynamic responses within and after extubation and also has a comparison between the effects of Lidocaine and Alfentanil in controlling the hemodynamic responses at the time of extubation.

\section{Materials and Methods}

This study was a randomized double-blind clinical trial which was done on 172 
candidate patients for orthopedic surgery of upper organs in Shahid Rajaee hospital dependent on Medical Sciences University in 2014. This study was approved with ethics code of 29.281 and meantime acquiring the written testimonial from the patients eligible for entering to the study, they were ensured that had right to be dispensed with continuing the work with researchers group and the research units were also ensured that all information remains confidential. Determination of the number of needed sample for doing the current study was calculated according to the researches accomplished in this field and by considering the power of $80 \%$ and the first kind error of $\alpha=0.05$.

The criteria for entering the patients to the study have included the age of 20 40 years old, weight of $60-80 \mathrm{~kg}$ and from two genders, the criteria for exiting from the study included existence of cardiovascular diseases, mental disease, spasm, glaucoma, numerous allergies, receipt of blood, blood products and addiction to the drugs. At first, the patients were monitored and then they received $0.03 \mathrm{mg} / \mathrm{kg}$ of Midazolam and $1 \mathrm{mcg} / \mathrm{kg}$ of Fentanil, then they were inducted by $2 \mathrm{mg} / \mathrm{kg}$ of Propofol and $0.5 \mathrm{mg} / \mathrm{kg}$ of Atracurium and anesthesia was continued by receiving $100 \mathrm{mcg} / \mathrm{kg}$ Propofol, $50 \%$ of $\mathrm{O}_{2}$ and $50 \%$ of $\mathrm{N}_{2} \mathrm{O}$. Then, the patients were divided into 4 groups (43 patients in each group) randomly and by using of colored cards that the Alfentanil ( $5 \mathrm{mcg} / \mathrm{kg})$, Lidocaine $(1 \mathrm{mcg} / \mathrm{kg})$, simultaneous amount of Alfentanil-Lidocaine and normal saline (with equal volume of $6 \mathrm{ml}$ ) were injected in order to the patients of groups A, B, C and D. The vital symptoms of patients including systolic and diastolic blood pressure and the number of heartbeats, existence or lack of existence of bucking were controlled and registered in 1, 5, 10 and 15 minutes after prescription of these drugs till extubation of patient. Extubation was done when the patient followed the orders (opening the eyes) and after extubation, the vital symptoms of patient were controlled and registered with interval of 5 minutes (till 15 minutes). According to the provided checklist, the data have been collected; according to the SPSS software, they have been entered to the computer and the data analysis was done by using of t-test, ANOVA, repeated measure ANOVA.

\section{Results}

172 patients (20 - 40 years old) were divided into four groups randomly (43 patients in each group). The patients of four groups didn't have significant difference with each other in terms of the demographic information.

The patients of all four groups were compared with each other in terms of the mean of systolic and diastolic blood pressure and number of heartbeats that as it is observed in the Figure 1, the systolic blood pressure was compared at the times of before injection of drug and 1, 5, 10, 15 and 20 minutes after injection of drug in four groups. The mean of systolic blood pressure in Alfentanil group has less amount than other groups and it has higher amount in the witness group; and statistically, Manova test indicated significant difference between the groups ( $p=0.01$ ). The mean of systolic blood pressure and number of heartbeats in the group of Alfentanil and composition of Alfentanil-Lidocaine had significant reduction $(\mathrm{p}<0.05)$ in comparison with the control and Lidocaine group. 
Also, the mean of average arterial blood pressure was compared at the times of before injection of drug and 1, 5, 10, 15 and 20 minutes after injection of drug in four groups. MANOVA test indicated that there is no significant statistical difference between the groups and the mean of the average arterial blood pressure is similar in the samples of all four groups $(\mathrm{p}=0.21)$ (Figure 2).

The diastolic blood pressure was compared at the times of before injection of drug and 1, 5, 10, 15 and 20 minutes after injection of drug in four groups. MANOVA test indicated that there is no significant statistical difference between the groups and the mean of diastolic blood pressure is similar in the samples of all four groups $(\mathrm{p}=0.09)$ (Figure 3 ).

As it is observed in the Figure 4, the mean of the number of heartbeats was

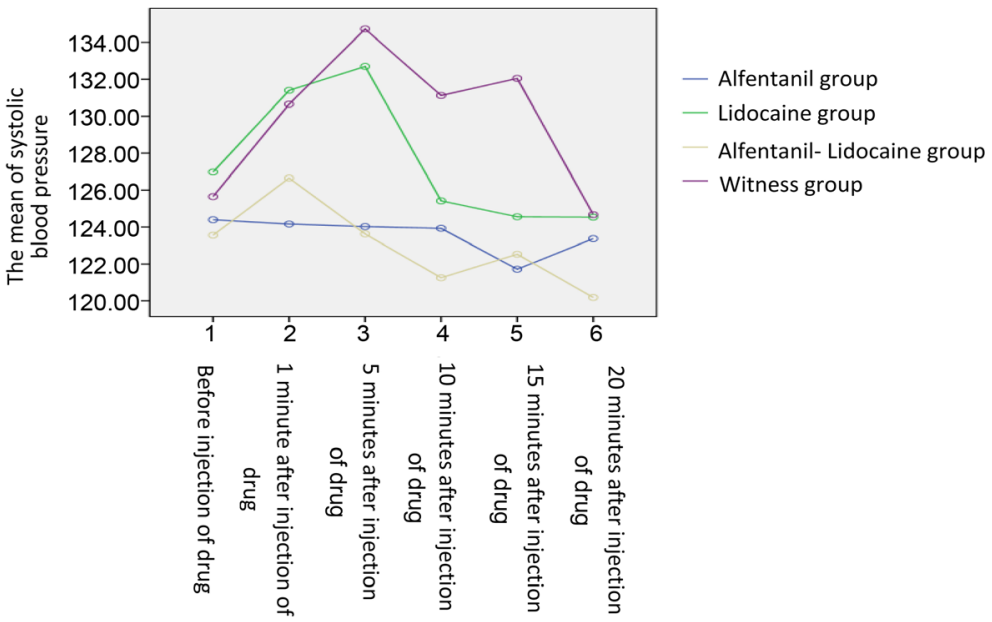

Figure 1. Comparison of the mean of systolic blood pressure in the specified times in four groups under study.

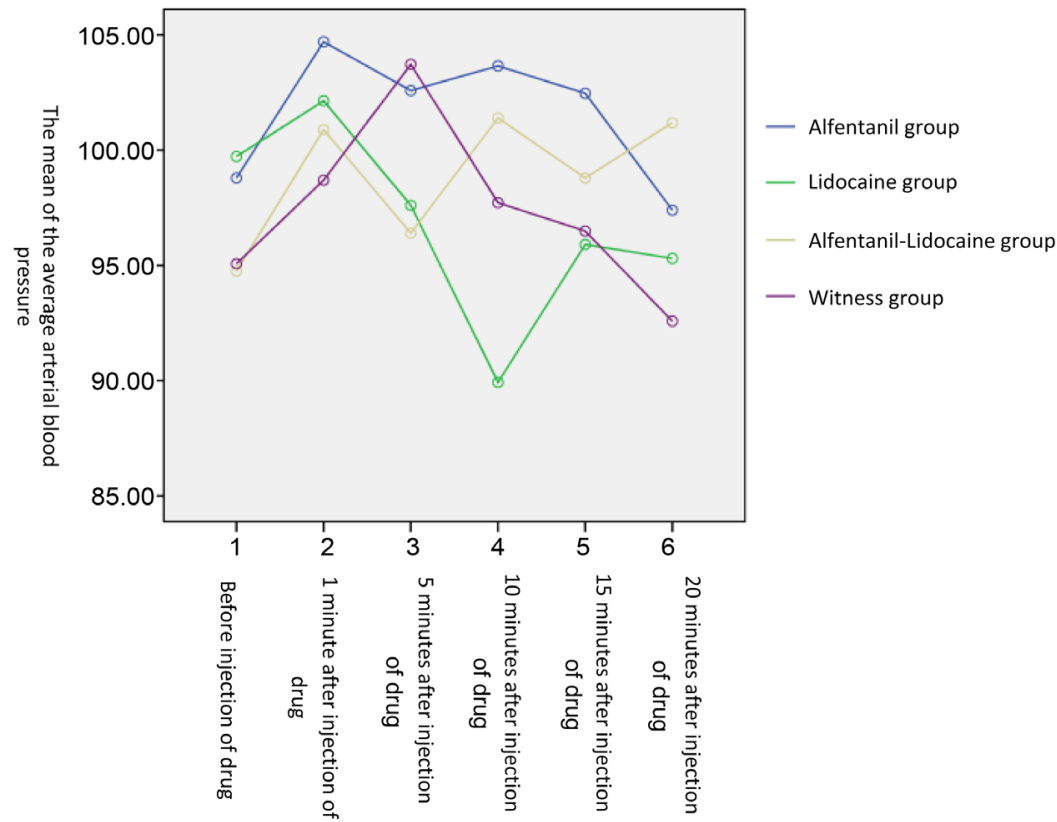

Figure 2. Comparison of the mean of average arterial blood pressure in the specified times in four groups under study. 


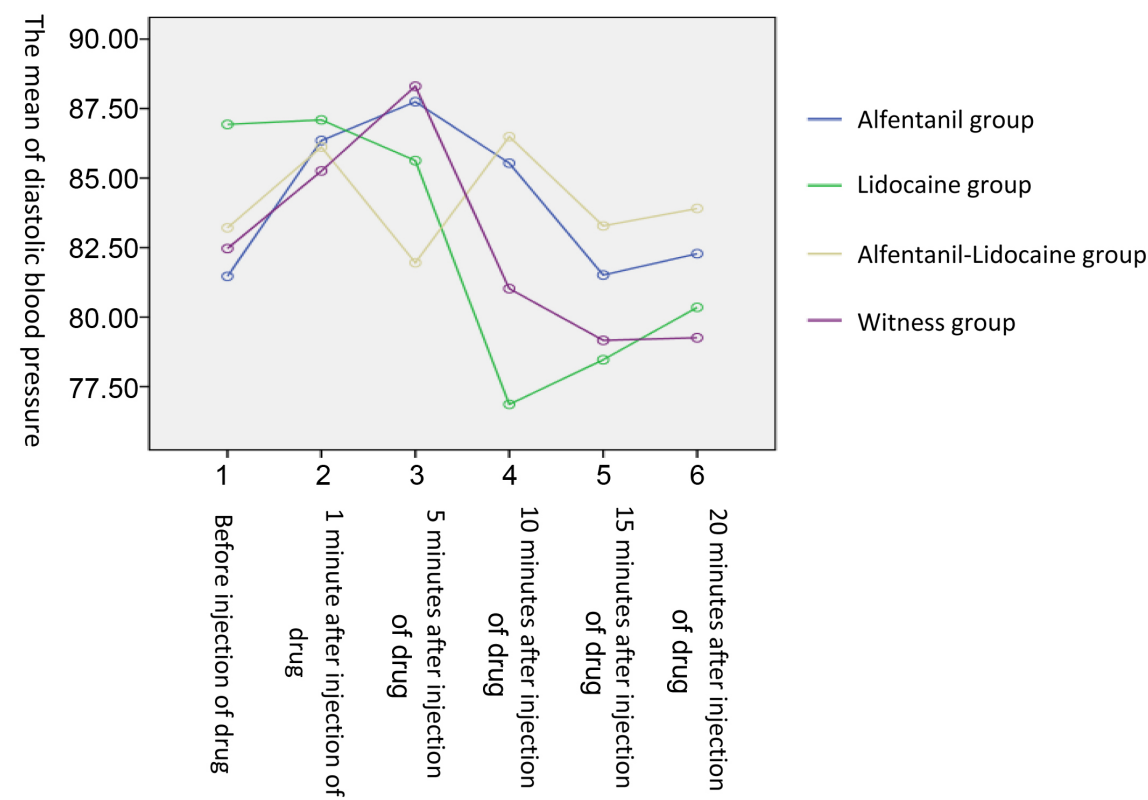

Figure 3. Comparison of the mean of diastolic blood pressure in the specified times in four groups under study.

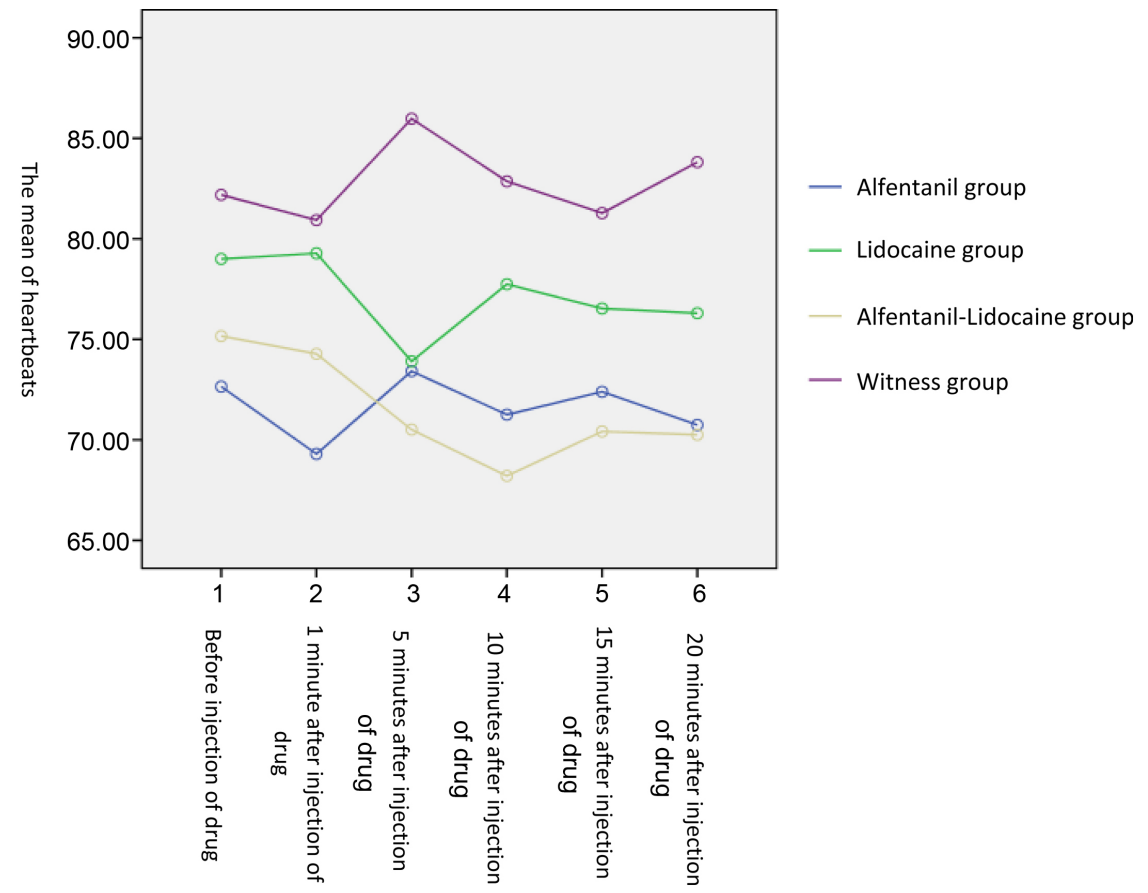

Figure 4. Comparison of the mean of the number of heartbeats in the specified times in four groups under study.

compared at the times of before injection of drug and 1, 5, 10, 15 and 20 minutes after injection of drug in four groups. As it has been indicated in this diagram, the mean of the number of heartbeats in two groups of Alfentanil and composition is in better range than two other groups and MANOVA test indicated that there is significant statistical difference between the groups.

The patients were controlled in terms of the tremor severity at the beginning 
of entering to the recovery. All three treatment groups had significant reduction in emergence of tremor after surgery in comparison with other group in a manner that the most frequency was related to the witness group and the least frequency was related to the Lidocaine group; and Alfentanil and composition groups had equal frequency. The statistical test of Chi-square indicated that there is significant difference between the groups in terms of bucking frequency $(\mathrm{p}=0.001)($ Table 1$)$.

\section{Discussion}

Generally, the results of study indicated that injection of Alfentanil and composition of two drugs of Alfentanil and Lidocaine caused good effect on systolic blood pressure and number of heartbeats; but, they hadn't any effect on diastolic blood pressure and average arterial pressure. Also, all three drugs caused to reduce the number of bucking cases after extubation. But, the mean of the time of drug injection till the time of extubation had become longer in injection of all three drugs.

Doing the extubation at the end of anesthesia can cause to create a series of hemodynamic changes such as increase of blood pressure and heartbeats that in many patients causes to emerge irreparable effects. Therefore, prevention from the intended changes is very vital for mentioned patients [13] and [14]. Although, the mechanism of increase of blood pressure and heartbeat within the intubation depends on the severe and short-term sympathetic stimulation arising from laryngoscopy in patient under general anesthesia; but, at the time of extubation, different factors such as the pain arising from wound, waking up from anesthesia and stimulation of chip have role in creating these hemodynamic changes [15]. Therefore, controlling these cardiovascular changes has been necessary and different drugs have been already suggested for this purpose such as Fentanyl, Esmolol Lidocaine, [16].

The effects of Lidocaine on blood pressure and heartbeat in responding to the extubation were studied by Bidowsky and his group, they poured $1.5 \mathrm{cc}$ of Lidocaine $4 \%$ into the chip tube for 3 - 5 minutes before extubation and within extubation, and they poured one $\mathrm{cc}$ of the second dose of Lidocaine $4 \%$ into the chip tube. No kind of increase of blood pressure and heartbeat was seen during 1 to 5 minutes after extubation [17]. Also, the studies had indicated that injection of Lidocaine into the chip tube causes to block the airway receptors and consequently constrain the cough that the study of Tavakkol et al., also indicated it;

Table 1. Comparison of the frequency of bucking amount in four groups under study.

\begin{tabular}{cccc}
\hline & With bucking & Without bucking & P value \\
\hline Alfentanil & $18(42 \%)$ & $25(58 \%)$ & \\
Lidocaine & $11(25.5 \%)$ & $32(74.5 \%)$ & 0.001 \\
Alfentanil-Lidocaine & $18(18 \%)$ & $25(58 \%)$ & \\
Witness & $31(72 \%)$ & $12(28 \%)$ & \\
\hline
\end{tabular}


but, in the continuation, Bidrowsky had reported that the changes of cardiovascular indexes are minimized in this method, a result that the study of Tavakkol didn't indicate it [18]. Also in a study, composition of Lidocaine with Captopril caused significant reduction in hemodynamic changes that in the Lidocaine group, these changes weren't lonely seen. Also in our study, Lidocaine lonely had good effect on reduction of bucking after extubation; but, it had no effect on reduction of hemodynamic symptoms.

Also in studying the time of extubation, Lidocaine like Alfentanil caused to increase the time of extubation; but, this difference wasn't significant in comparison with witness group that these results are similar with the study of Anderson and et al., in a manner that in their study, injection of Lidocaine doesn't cause to increase the time of sedation and anesthesia for extubation [19].

Prescription of narcotic drugs intravenously before waking up from anesthesia is useful for prevention from cough, agitation and hemodynamic responses. Delay of recovery time, nausea and vomit arising from narcotic drugs are from the defects of prescription of narcotic drugs. Prescription of a short-effect narcotic drug is a trustable and safe method for prevention from cough during waking up from anesthesia.

Alfentanil has been a short-effect opioid which has a short half-life too. In the study of Mar'ashi, it was indicated that $10 \mu \mathrm{g} / \mathrm{kg}$ of Alfentanil caused to reduce and stabilize the systolic blood pressure after extubation. Also in his study, it was indicated that injection of Remifentanil in comparison with Alfentanil causes to reduce the average arterial blood pressure and diastolic blood pressure [20]. Also in our study, Alfentanil caused to reduce the systolic blood pressure; but, it didn't have any effect on average arterial blood pressure and diastolic blood pressure in comparison with other groups that these results are aligned with above study.

Also in the study of Fuhrman, comparison of Smolol and Alfentanil in reduction of hemodynamic side effects after extubation indicated that Alfentanil like Smolol caused to reduce the hemodynamic effects after extubation; but, it caused to increase the time of extubation [21] that in our study, Alfentanil group in comparison with the group of Alfentanil and Lidocaine composition and witness group caused to increase the time of extubation that this difference was significant. But, in the study of Mendel, prescription of Alfentanil caused to reduce bucking, coughing and hemodynamic effects after extubation without elongation of extubation time [22].

Also, in relation with the amount of creation of airway reflexes after extubation like coughing and bucking, in the study of Sadeghi and et al., it was indicated that Alfentanil in comparison with Lidocaine had caused to reduce the amount of these side effects after extubation without elongation of extubation time [23], while in our study, it was indicated that the frequency of bucking amount in the Lidocaine group was less than two other treatment groups; but, generally all three groups had less amount than witness group that this difference was also significant statistically. 


\section{Conclusion}

With regard to the results of this study that we witnessed the reduction of the mean of SBP and heartbeat in the Alfentanil and Alfentanil-Lidocaine groups and also reduction of bucking amount in both groups but in less amount in Lidocaine group, we didn't have significant reduction in the Lidocaine group in terms of the amount of heartbeat and SBP. It can be concluded that the composition of Lidocaine and Alfentanil can cause good effect on reduction of side effects arising from extubation, but adding Lidocaine doesn't cause better effect and it is the important point in increase of the time of extubation in comparison with witness group that this 3-minute difference can not reduce the importance of this issue so much.

\section{Limitation}

This study had a limitation and it was about patients' consent. Many patients did not want to enter the study.

\section{References}

[1] Miller, R.D. (2010) Miller's Anesthesia. Churchill Livingstone/Elsevier, London.

[2] Lee, J., Koo, B., Jeong, J., Kim, H. and Lee, J. (2011) Differential Effects of Lidocaine and Remifentanil on Response to the Tracheal Tube during Emergence from General Anaesthesia. British Journal of Anaesthesia, 106, 410-415. https://doi.org/10.1093/bja/aeq396

[3] Nho, J.-S., Lee, S.-Y., Kang, J.-M., Kim, M.-C., Choi, Y.-K., Shin, O.-Y., Kim, D.-S. and Kwon, M.-I. (2009) Effects of Maintaining a Remifentanil Infusion on the Recovery Profiles during Emergence from Anesthesia and Tracheal Extubation. British Journal of Anaesthesia, 103, 817-821. https://doi.org/10.1093/bja/aep307

[4] Aouad, M.T., Al-Alami, A.A., et al. (2009) The Effect of Low-Dose Remifentanil on Responses to the Endotracheal Tube during Emergence from Anesthesia. Anesthesia \& Analgesia, 108, 1157-1160. https://doi.org/10.1213/ane.0b013e31819b03d8

[5] Murray, M.J. (2002) Anaesthesia for Thyroid Surgery. In: James, M., Ed., American Society of Critical Care Anesthesiologists. Lippincott Williams \& Wilkins, Philadelphia, 168-169.

[6] Brendan, J. (2006) Anatomy and the Cough Reflex. Anesthesia \& Analgesia, 129, 335-475.

[7] Prichard, J.S., French, J.S. and Alvar, N. (2006) Clinical Evaluation of the ABL-77 for Point of Care Analysis in the Cardiovascular Operating Room. The Journal of Extra-Corporeal Technology, 38, 128-133.

[8] Lee, B., Lee, J.-R. and Na, S. (2009) Targeting Smooth Emergence: The Effect Site Concentration of Remifentanil for Preventing Cough during Emergence during Propofol-Remifentanil Anaesthesia for Thyroid Surgery. British Journal of Anaesthesia, 102, 775-778. https://doi.org/10.1093/bja/aep090

[9] Opioids, F.K. (2010) Lidocaine Administration via Endotracheal Tube. In: Miller, R., Ed., Anesthesia, Churchill Livingstone, USA, 769-820.

[10] Hohlrieder, M., Tiefenthaler, W., Klaus, H., Gabl, M., Kavakebi, P., Keller, C. and Benzer, A. (2007) Effects of Total Intravenous Anesthesia and Balanced Anesthesia on the Frequency of Coughing during Emergence from Anesthesia. British Journal 
of Anaesthesia, 99, 587-591. https://doi.org/10.1093/bja/aem203

[11] Irwin, R.S. (2006) Complications of Cough: ACCP Evidence-Based Clinical Practice Guidelines. Chest, 129, 54S-58S.

[12] Jang, Y.H. and Oh, S.R. (2005) Intravenous Lidocaine Does Not Reduce Emergence Agitation or Pain after Sevoflurane Anesthesia in Children. Korean Journal of Anesthesiology, 49, S14-S19. https://doi.org/10.4097/kjae.2005.49.6.S14

[13] Jee, D. and Park, S.Y. (2003) Lidocaine Sprayed down the Endotracheal Tube Attenuates the Airway-Circulatory Reflexes by Local Anesthesia during Emergence and Extubation. Anesthesia \& Analgesia, 96, 293-297.

[14] Minogue, S.C., Ralph, J. and Lampa, M.J. (2004) Laryngotracheal Topicalization with Lidocaine before intubation Decreases the Incidence of Coughing during Emergence from Anesthesia. Anesthesia \& Analgesia, 99, 1253-1257. https://doi.org/10.1213/01.ANE.0000132779.27085.52

[15] Bidwaski, A.V., Stanley, T.H. and Bidwai, V.A. (1998) Blood Pressure and Pulse Rate Response to Extubation with and without Prior Tracheal Anesthesia. Canadian Anaesthetists' Society Journal, 25, 416-418.

[16] Tavakol, K. and Ghafarian, H. (2008) The Effect of Lidocaine Administration via Endotracheal Tube before Extubation in Cataract Operation in Decrease of Incidence of Cough and Laryngospasm in Sajad Hospital. Iranian Journal of Critical Care Nursing, 2, 122-126.

[17] Andrzejowski, J. and Francis, G. (2002) The Efficacy of Lidocaine Administered via the LITA Tracheal Tube in Attenuating the Extubation Response in Beta-Blocked Patients Following Craniotomy. Anesthesia, 57, 387-403. https://doi.org/10.1046/j.1365-2044.2002.2466_4.x

[18] Mar'ashi, S.M., Azimaraghi, O., Asadi, A., Barzin, G. and Movafegh, A. (2014) Comparison of Remifentanil and Alfentanil Bolus Dose on Extubation Emergence Hemodynamic Profiles, a Randomized Double-blinded Placebo-Controlled Trial. Academic Journal of Surgery, 1, 52-56.

[19] Fuhrman, T.M., Ewell, C.L., Pippin, W.D. and Weaver, J.M. (1992) Comparison of the Efficacy of Esmolol and Alfentanil to Attenuate the Hemodynamic Responses to Emergence and Extubation. Journal of Clinical Anesthesia, 4, 444-447. https://doi.org/10.1016/0952-8180(92)90216-N

[20] Mendel, P., Fredman, B. and White, P.F. (1995) Alfentanil Suppresses Coughing and Agitation during Emergence from Isoflurane Anesthesia. Journal of Clinical Anesthesia, 7, 114-118. https://doi.org/10.1016/0952-8180(94)00024-X

[21] Sadegi, M., Firozian, A., Ghafari, M.H. and Esfehani, F. (2008) Comparison in Effect of Intravenous Alfentanil and Lidocaine on Airway-Circulatory Reflexes during Extubation. International Journal of Pharmacology, 4, 223-226. https://doi.org/10.3923/ijp.2008.223.226

[22] Morimatsu, H., Rocktäschel, J., Bellomo, R., Uchino, S., Goldsmith, D. and Gutteridge, G. (2003) Comparison of Point-of-Care versus Central Laboratory Measurement of Electrolyte Concentrations on Calculations of the Anion Gap and the Strong Ion Difference. Anesthesiology, 98, 1077-1084.

https://doi.org/10.1097/00000542-200305000-00009

[23] Kendall, J., Reeves, B. and Clancy, M. (1998) Point of Care Testing: Randomized Controlled Trial of Clinical Outcome. British Medical Journal, 316, 1052-1057. https://doi.org/10.1136/bmj.316.7137.1052 
Submit or recommend next manuscript to SCIRP and we will provide best service for you:

Accepting pre-submission inquiries through Email, Facebook, LinkedIn, Twitter, etc. A wide selection of journals (inclusive of 9 subjects, more than 200 journals)

Providing 24-hour high-quality service

User-friendly online submission system

Fair and swift peer-review system

Efficient typesetting and proofreading procedure

Display of the result of downloads and visits, as well as the number of cited articles Maximum dissemination of your research work

Submit your manuscript at: http://papersubmission.scirp.org/

Or contact ijcm@scirp.org 